\title{
FUNDAMENTALISMOS JUDÍOS Y HOLOCAUSTO: OPINIONES DIVERGENTES Y CONTRAPOSICIONES
}

\author{
JEWISH FUNDAMENTALISMS AND THE HOLOCAUST: \\ DIVERGENT AND CONTRASTING OPINIONS
}

\section{FELIPE ORELLANA GALLARDO 1}

\section{RESUMEN}

El presente artículo pretende ilustrar acerca de la concepción que tienen los fundamentalismos judíos sobre el Holocausto (o Shoá en hebreo). El Holocausto se presenta como uno de los mayores genocidios de la Historia y acontecido, principalmente, al pueblo judío. Sin embargo, en un contexto de desaprobación a este acontecimiento, parte de los movimientos fundamentalistas judíos conciben este suceso como la aplicación de un castigo divino. Dentro de estos movimientos, hay claras divergencias con respecto a la concepción del Holocausto y a su vinculación con la modernidad; los movimientos aquí estudiados Neturei Karta y Gush Emunim, que se enmarcan dentro de la ultraortodoxia y el sionismo religioso, respectivamente, muestran divergencias con respecto a la concepción del Holocausto y a la asimilación a la modernidad y también con respecto al sionismo.

Palabras clave: Fundamentalismo, Neturei Karta, Gush Emunim, holocausto (Shoá).

\section{ABSTRACT}

This article attempts to illustrate the concept that Jewish fundamentalisms have about the Holocaust (Shoah in Hebrew). The Holocaust is presented as one of the greatest genocides in history and occurring primarily to the Jewish people. However, in a context of disapproval of the event, part of the Jewish fundamentalist movements conceived this event as the application of divine punishment. Within Jewish fundamentalism movements there are differences regarding the design of the Holocaust and

\footnotetext{
${ }^{1}$ Sociólogo, Universidad Alberto Hurtado. Diplomado en Ciencias de la Religión, Universidad de Chile.E-mail: forellanagallardo@gmail.com
} 
its relationship to modernity. The movements studied here, Neturei Karta and Gush Emunim, which are part of ultra-Orthodoxy, and religious Zionism, respectively, show differences regarding the concept of Holocaust and assimilation to modernity and also regarding Zionism.

Keywords: Fundamentalism, Neturei Karta, Gush Emunim, holocaust (Shoah).

Recibido: 27.11.12. Aceptado: 20.03.13.

\section{INTRODUCCIÓN}

$\mathrm{E}$

NTRE LOS NUMEROSOS y agitados sucesos del "siglo XX corto", que comprende desde 1914 a 1991 (Hobsbawm, 1998), se incluyen dos gue-

rras mundiales, revoluciones, la configuración de la política mundial en dos bloques, existe uno que merece especial atención por su singularidad y particularidad histórica: El Holocausto -o Shoá en hebreo-. Este acontecimiento -que cobró la vida de 6 millones de judíos, entre otras víctimas- se tiene como una de las mayores desgracias que han acontecido en la historia de la humanidad, ya que "'es un crimen singular'. No porque todo evento, toda persona, cada época es única, cosa que todo el mundo sabe, sino porque la dimensión alcanzada en ese asesinato masivo ideológico-industrial carece de precedentes, es inconmensurable y resulta casi inconcebible" (Küng, 2007: 220). Es un acontecimiento sin precedentes por su magnitud y en el que se ve implicado, de una u otra forma, gran parte del aparato burocrático alemán, desde funcionarios redactando un memorando o coordinando los horarios de los trenes a los campos de concentración, hasta aquellos que directamente efectuaban las ejecuciones. El Holocausto y la Segunda Guerra Mundial tuvieron un papel decisivo no sólo en el pueblo judío -aunque la "solución final” y la creación del Estado de Israel son sucesos directamente ligados a las consecuencias de la dictadura de Hitler y a la historia contemporánea del judaísmo- sino también en la configuración posterior del siglo XX.

En una situación con tal herencia, y en el marco de las identidades judías contemporáneas (Caro, 2008a), resulta de particular interés la postura del judaísmo ultraortodoxo con respecto a esta temática y al sionismo, ya que para esta corriente

el exterminio es presentado como el castigo de Dios hacia aquellos que transgredieron los mandamientos de la Torá y buscaron asemejarse a las naciones creando un Estado judío semejante a los otros estados moder- 
nos. La ideología ultraortodoxa, en oposición al sionismo, considera el horror de Auschwitz como la sanción ejemplar de todo proyecto político judío que no tenga su única inspiración en el estricto respeto de la Torá (Caro, 2008a: 85).

No se alude con esto a minimizar los alcances del Holocausto por parte de la ultraortodoxia, pero lo que merece atención es su interpretación como aplicación de justicia. Esta postura da a entender que fue el castigo aplicado a aquellos que no se rigieron estrictamente por el canon. En un contexto de rechazo casi unánime a la doctrina racial del régimen nazi, merece atención la interpretación de una parte constituyente del pueblo directamente afectado; pequeña pero que resurge a inicios del siglo XXI junto con las identidades judías laicas (Caro, 2008b). Una indagación en la visión de la ultraortodoxia judía en relación a este hecho amerita un análisis más detallado que intente dar cuenta cómo es que se percibe este acontecimiento.

El objetivo principal de este artículo es estudiar la relación que se da entre el fundamentalismo judío y el Holocausto (la Shoá) desde una perspectiva sociológica. Como objetivos específicos, consideraremos: a) estudiar distintas corrientes al interior del fundamentalismo judío; b) analizar de qué modo ellos conforman sus identidades (culturales, religiosas, nacionales).

Se puede señalar, con respecto a la modernidad -de forma genéricaque corresponde a "los modos de vida u organización social que surgieron en Europa desde alrededor del siglo XVII en adelante y cuya influencia, posteriormente, los ha convertido en más o menos mundiales. Esto asocia a la modernidad a un período de tiempo y a una inicial localización geográfica" (Giddens, 1999: 15) y cuyos rasgos característicos son "los procesos de urbanización, la industrialización, la democratización y el surgimiento de una concepción empírica y analítica del conocimiento" (Wagner, 1997: 27). Con respecto a la relación entre sociología y modernidad hay un clara vinculación desde los inicios mismos de la disciplina, pues "¿qué otra cosa es la sociología, sino un intento sistemático por entender la sociedad moderna?" (Wagner, 1997: 11) y se concibe a la sociología como "la disciplina más comprometida en el estudio de la vida social moderna" (Giddens, 1999: 17).

La hipótesis que sustenta este trabajo es que al interior de los fundamentalismos judíos existen dos concepciones opuestas y excluyentes con respecto a la Shoá: una representada por la ultraortodoxia judía, que ve la 
Shoá como parte de un castigo divino; y otra, sustentada por el sionismo religioso, que lo considera como parte de un proceso que promueve la conformación de un hogar nacional judío en Israel.

\section{CARACTERIZACIÓN DE LOS FUNDAMENTALISMOS JUDÍOS}

Antes de entrar propiamente en la materia de este artículo, es necesario precisar qué se entiende por fundamentalismo. El fundamentalismo es un movimiento religioso que nace en Norteamérica en el siglo XIX; este movimiento consigue alcanzar un consenso sobre algunos fundamentals religiosos o hechos fundamentales; se constituye en diametral oposición a la modernidad y sus componentes (la secularización, el modernismo y el darwinismo en ciencias naturales); y frente al modernismo se remite a la Biblia y al dogma, casi siempre de forma irreflexiva (Kienzler, 2000). Las anteriores eran características pensadas específicamente para el cristianismo, pero éstas se hacen extensivas a las otras religiones monoteístas, e incluso al budismo, debido a que en el fundamentalismo está muy presente tanto la ortodoxia -la certeza de fe que poseen los fieles en cuanto a su saber religioso como a sus creencias- como la ortopraxis -velar por que la conducta dentro de una comunidad religiosa sea la adecuada y esté sometida a sanction- (Kienzler, 2000).

En primera instancia para los efectos de este artículo, y sumado a lo recién mencionado, se considera adecuado englobar al sionismo religioso y a las distintas corrientes ultraortodoxas dentro de la denominación fundamentalista, como habitualmente se hace en conjunto con el cristianismo e Islam, por una característica central que se observa en las tres religiones del libro y sus facciones más extremas: la total oposición y antítesis a la modernidad ilustrada y secularizada. Lo esencial es que "los fundamentalismos en las tres religiones monoteístas rechazaban la modernidad" (Armstrong, 2009: 349). Es esta característica central la que permite afirmar aquí que sí se puede hablar de fundamentalismo, independiente de la polémica que evidencian autores como Azria (1985), Caro (2004) o Kienzler (2000), porque es en la modernidad cuando estos grupos literalmente toman forma y también cuando se proponen rechazarla. Este rechazo a la modernidad es el aspecto crucial que se considerará en este trabajo ya que: "los fundamentalismos, en las tres religiones monoteístas, se oponen al logos pragmático que domina a la sociedad moderna, que excluye lo espiritual y rechaza las limitaciones impuestas por lo sagrado" (Armstrong, 2009: 268). A conti- 
nuación, consideraremos en forma más detallada a dos movimientos dentro del fundamentalismo judío, Neturei Karta, perteneciente a la ultraortodoxia judía; y Gush Emunim, correspondiente al sionismo religioso.

\section{Ultraortodoxia judía: Neturei Karta}

Avi-Hai (1993) propone que la ortodoxia es un fenómeno moderno porque surge como reacción a los desafíos que imponía la Ilustración y la emancipación judía. La noción de ultraortodoxia -vertiente a la que pertenece Neturei Karta- no existía; pero el fenómeno se encontraba en ciernes: aquellos que se oponían a la cultura moderna secular y al sionismo (rasgo, este último, distintivo de Neturei Karta). Este grupo se enmarca dentro de lo que Azria (1985) denomina el judaísmo integral, el ala ultraortodoxa del judaísmo, que ha resistido y resiste de forma más dura los efectos de la modernidad; rechazan el modelo de la sociedad civil e intenta perpetuar el modelo de judaísmo tradicional. La estrategia para lograr tal cometido es el separatismo, de forma externa, y el maximalismo, de forma interna al grupo; el primero refiere al aislamiento en términos: a) políticos, ya que no reconocen la legitimidad del Estado de Israel; se consideran aún en exilio (hasta que Dios diga lo contrario) y no tienen ninguna relación con las instituciones civiles; b) religiosos, puesto que se encuentran separados del resto de la comunidad judía y no consideran la autoridad del rabinato de Israel; c) geográficos, ya que viven en barrios sumamente delimitados y d) culturales, rechazan hablar hebreo y utilizan el yiddish (debido a su tradición askenazí); rechazan todos los medios de comunicación de masas y utilizan una vestimenta heredada de la diáspora, concretamente el vestir de la tradición lituana: "el traje negro, las patillas y la kasherut" (Kepel, 2005: 213). El maximalismo al que alude Azria (1985) tiene relación con la extensión máxima de la ley religiosa, que se orienta en tres direcciones: a) el detalle de la observancia religiosa; la Halajá (ley religiosa judía) determina todos los aspectos de la vida; b) existe una interpretación estricta de la ley y c) tendencia a extender lo más posible el campo de aplicación de la ley.

\section{Sionismo religioso: Gush Emunim}

Otro movimiento fundamentalista religioso en que nos centraremos es Gush Emunim. La postura claramente sionista de Gush Emunim constituye 
un claro antagonismo a la de Neturei Karta y su concepción sobre el Holocausto también difiere, como se mostrará más adelante. Gush Emunim constituye una suerte de antítesis del primer movimiento señalado y se conforma después de la anexión de territorios, sagrados para el judaísmo, producto de la Guerra de los Seis Días. Su origen data de febrero de 1974 cuando "una serie de rabinos, de laicistas militantes, seguidores del rabino Kook y otros sionistas religiosos, que habían servido en el ejército israelí y combatido en las guerras de Israel, formaron un grupo al que denominaron Gush Emunim (Bloque de los Creyentes)" (Armstrong, 2009: 350) y "su objetivo explícito, inequívocamente proclamado, es afianzar la soberanía israelí sobre toda la Tierra de Israel (Eretz Israel); lo cual significa antes que nada oponerse a la retirada de los territorios ocupados y, por el contrario, colonizarlos para asegurar un perdurable dominio judío" (Kepel, 2005: 225-226).

Las diferencias de Gush Emunim con Neturei Karta son notorias, en lo que respecta al sionismo y acción política; ya que mientras los segundos se apartan del mundo secular para dedicarse al estudio y observancia estricta de la Torá, los miembros del Gush realizan medidas concretas y muy "prácticas" para llevar a cabo sus objetivos. Como señala Lustick (1987), el Gush Emunim insiste que la acción política es el medio para alcanzar una rápida transformación de la sociedad israelí y cuentan con apoyo electoral. Más arriba se señaló como característica central de los fundamentalismos la oposición a la modernidad, esto es claramente visible en el caso de $\mathrm{Ne}$ turei Karta, pero no es tan visible una posición radicalmente antimoderna para el caso de Gush Emunim; lo anterior se evidencia en que las familias de colonos de Gush visten, se comportan, viven y actúan a la manera occidental moderna, por ejemplo, el televisor es de gran importancia en la socialización de los niños (como puede ser en cualquier país occidental), a diferencia de la prohibición hacia este medio de comunicación en la ultraortodoxia. También los colonos cumplen algunos roles en el mundo laboral y en la vida política nacional, a través de la realización del servicio militar o en puestos del aparato estatal y el estudio de la Torá se realiza en situaciones cotidianas y no se limita a la yeshiva (Caro, 2004), como acontece en la ultraortodoxia. Se podría afirmar, a modo de síntesis de este punto, que mientras Neturei Karta rechaza la modernidad y sus componentes -en una actitud claramente antimoderna-, Gush Emunim los acepta y emplea para la consecución de sus fines -en una actitud moderna-. 
Cuadro 1. Contraposiciones Neturei Karta - Gush Emunim en torno al sionismo y otros temas.

\begin{tabular}{|l|l|l|}
\hline Posición frente a & Neturei Karta & Gush Emunim \\
\hline Sionismo & Rechazo & Adherente \\
\hline Modernidad & Rechazo & Adherente \\
\hline Estado & Rechazo & Participación \\
\hline Sociedad civil & Rechazo & Participación \\
\hline Vida política & Rechazo & Participación \\
\hline
\end{tabular}

Fuente: Elaboración propia.

Las anteriores eran características generales de los fundamentalismos judíos con respecto a algunos tópicos de interés, pero además es necesario ilustrar sobre el rol de éstos en la sociedad israelí. Se mencionó que Neturei Karta rechaza la sociedad secular y se recluye en barrios sumamente delimitados; esto es evidente tanto en los EE.UU. como en Israel, donde en "los distritos antisionistas de Jerusalén comparan a los líderes políticos del Estado de Israel con Hitler" (Armstrong, 2009: 265). Los colonos del Gush, de igual manera, se agrupan en sectores específicos, como pueden ser los territorios conquistados posteriormente a la Guerra de los Seis Días. Otorgan una importancia capital a la ciudad de Jerusalén, ya que "es vista como el centro espiritual y físico del mundo, con el Templo en su corazón" (Zeidan, 2006: 234); y existe una ligera participación con respecto a la sociedad civil.

Neuser (1992) afirma que, entre las consecuencias del Holocausto, amplios sectores del judaísmo "que aún quedaban en Occidente y los que se habían establecido en el Estado de Israel optaron decididamente por la integración" (p. 87), ya sea a las distintas sociedades en la diáspora o a la vida del naciente Estado de Israel. Afirmación muy discutible, si se considera como impacto político-cultural aplicada a los fundamentalismos judíos, porque se podría cuestionar en qué grado Neturei Karta ha tenido intereses integracionistas ya sea en los EE.UU. o Israel, desde que el movimiento se formó en 1938, debido a su manifiesto segregacionismo/aislacionismo (Thompson, 2007). Neuser (1992) considera adecuado englobar a los fundamentalismos derechamente como "segregacionistas", ya que "rechazan cualquier clase de relación con el mundo que los rodea" (p. 88), sólo se 
relacionan, trabajan y se prestan auxilio entre miembros de la comunidad a la que pertenecen. En términos de cifras podríamos añadir, que la facción ultraortodoxa antisionista - de la que es representante Neturei Karta-, constituye aprox. el 4,5\% del componente religioso de la sociedad israelí que representa un 20\% del total; mientras que el Gush representa el 8,5\% del mismo (Zeidan, 2006), pero en términos prácticos, como ya se mencionó, ambos movimientos tienen una tendencia marcada -de mayor o menor forma- a la segregación/aislación en relación a la sociedad civil de Israel.

\section{Formación identitaria}

La modernidad, donde los fundamentalismos toman forma, es una época en que hay una exaltación del individuo y un aparente abandono de la presencia divina, por mencionar algunas de sus características. En palabras de Zigmunt Bauman hay en la modernidad una "creencia en la autosuficiencia, se dio una mezcla de 'podemos' y 'debemos'. No podemos ser otra cosa que autosuficientes porque se nos ha abandonado a nuestra astucia y a nuestros recursos propios, aunque escasos" (Bauman y Tester, 2002: 106). Existe una autosuficiencia del individuo en la modernidad (y también una ausencia de Dios) ya que "la fórmula moderna de vida humana en la tierra [se ha articulado, según que] los humanos son los únicos que cuidan de todo lo humano y, por lo tanto, lo único que importa a los humanos es aquellos de lo que los humanos pueden cuidar" (Bauman, 2001: 211). A estos elementos recién mencionados hay que añadir la incertidumbre inherente a la modernidad; quiere decir esto que el individuo moderno no tiene patrones fijos o estables a los cuales atenerse y sus vidas transcurren con elementos impredecibles o inesperados; en contraposición al individuo premoderno, en los cuales sus vidas tienen muy poca incertidumbre ya que sus existencias están labradas y determinadas desde el nacimiento y sólo la muerte presenta un elemento sorpresivo en una existencia claramente determinada (Bauman, 2001).

Se hace alusión a la autosuficiencia, el énfasis en el individuo y la incertidumbre moderna porque son factores que inciden en la formación de los fundamentalismos y en cómo los miembros de estos movimientos religiosos establecen su identidad en base a la pertenencia a estos movimientos. La modernidad provoca tensiones entre libertad y comunalidad (Bauman, 2003) o entre autonomía y sometimiento (Wagner, 1997); se prefieren las certezas que entrega una comunidad claramente establecida, aunque al op- 
tar por ésta se disminuye la libertad dado los constreñimientos que el grupo impone, puesto que la modernidad provoca que "las emociones generadas por la incertidumbre existencial se canalicen en una frenética búsqueda de la 'seguridad en la comunidad'” (Bauman, 2003: 139).

Los fundamentalismos judíos, bajo esta óptica, obedecerían a comunidades claramente definidas y con un fuerte componente moral que determinarían todos los aspectos de la vida de sus integrantes (cuestión muy latente en el caso de Neturei Karta), reduciendo de esta manera la incertidumbre y diferenciándose claramente de los herejes seculares. La comunidad, ya sea el grupo de colonos de Gush Emunim o los estudiosos de la Torá de Neturei Karta, no sólo establece patrones claros a los cuales atenerse, sino que también establece la gran diferencia entre ella y los otros, los en este caso infieles que no vivencian como una época mesiánica el expansionismo israelí o no siguen los preceptos de la ley. Esto acontece porque "comunidad significa mismidad, en tanto que 'mismidad' significa la ausencia del Otro, especialmente de otro obstinadamente diferente, capaz de desagradables sorpresas y malicias precisamente por razón de su diferencia" (Bauman, 2003: 137). Por último, la conformación identitaria por medio de la comunidad, en este caso Gush Emunim y Neturei Karta, trae consigo la diferenciación con los otros.

\section{CARACTERIZACIÓN DEL HOLOCAUSTO}

Antes de entrar propiamente en materia del Holocausto es necesario realizar una precisión conceptual con respecto al rechazo u odio hacia el judaísmo comúnmente conocido como antisemitismo (elemento clave al momento de intentar explicar la política nazi hacia los judíos). Bauman y Tester (2002) señalan que la animadversión hacia los judíos proviene de considerarlos como "otros" que atraviesan la frontera entre los cristianos y los paganos, "eran los hermanos mayores de los cristianos que optaron por convertirse en paganos al rechazar la misión divina de Cristo" (Bauman y Tester, 2002: 112); se les asimila a monstruos que tienen oculto poderes $y$ que, más significativamente, se diferencian de las comunidades en que se insertan, "la actitud endémica del cristianismo respecto a los judíos era más de alosemitismo (del latín allus, 'otro') que de antisemitismo: a los judíos no se les podía aplicar normas ordinarias; los judíos eran distintos del resto de los mortales y eso exigía que se los separase y que se les sometiera a un tratamiento específico" (Bauman y Tester, 2002: 112-113); que el judío 
constituya el "otro" se debería a "la dispersión, la concepción religiosa, el sistema de normas éticas y el estilo de vida que se ajusta a principios vitales, todo eso provoca el antisemitismo, cuyos orígenes son antiquísimos. El judío es distinto, por lo tanto, odiado" (Biletzky, 1981: 67). Por la razón de no constituir una xenofobia cualquiera, por tratar con mitos antiquísimos como el de matar a Dios o comer no judíos, el odio hacia los judíos es denominado más adecuadamente bajo otro concepto: "Judeofobia es más precisa, porque en el prefijo señala el verdadero destinatario de esta aversión, el judío, y en el sufijo alude a su carácter irracional... [Judeofobia] en ciencias sociales tiene una connotación más cercana al odio, y no al temor, como en xenofobia: odio a los extranjeros" (Perednik, 1999: 22). Por lo recién expuesto, en el presente artículo el tradicional concepto de "antisemitismo" será reemplazado por el no tan difundido, pero más preciso, de "judeofobia".

Con respecto al Holocausto, se puede mencionar que corresponde a un genocidio dirigido hacia el pueblo judío; aunque éstos no fueron las únicas víctimas de la ideología nazi, ya que opositores del régimen, minusválidos física o mentalmente, homosexuales y miembros de etnias como la gitana también se encontraron entre las víctimas. Según Hilberg (2005) "las actividades destructivas abarcaron tres categorías generales de individuos: 1) personas aquejadas de enfermedades o discapacidades, 2) aquéllos considerados amenazadores o peligrosos debido a su comportamiento y 3) los pertenecientes a determinadas nacionalidades" (p. 1100). La Shoá se compuso, a grandes rasgos, de cuatro fases determinadas. "Las medidas se introdujeron en el siguiente orden: en primer lugar, se definió el concepto de judío; después se inauguraron las operaciones de expropiación; en tercer lugar, se concentró a los judíos en guetos; finalmente, se tomó la decisión de aniquilar a los judíos europeos" (Hilberg, 2005: 67).

\section{FUNDAMENTALISMOS JUDÍOS Y CONCEPCIÓN DEL HOLOCAUSTO}

La ultraortodoxia tiene una visión definida, la posición de Neturei Karta es clara con respecto a la Shoá: constituye un castigo divino frente al sionismo y a la desobediencia a la Torá. La posición de Gush Emunim es en sentido opuesto, se concibe este acontecimiento como un aviso para el asentamiento definitivo en Eretz Israel. Para la ultraortodoxia "el sionismo era la herejía por excelencia, una arrogancia descarada que sacudía las mismas bases 
del mundo. ¡No era de extrañar que Dios hubiese enviado el Holocausto!” (Armstrong, 2009: 263) y la asimilación a la modernidad, así como una práctica débil del libro sagrado eran factores que incidieron en el exterminio judío.

Las conferencias negacionistas sobre el Holocausto, celebradas en Teherán el 2006, constituyen un lugar importante para identificar la posición de Neturei Karta; en ellas las posturas de los diversos rabinos permiten afirmar aquí que no adhieren al negacionismo y también permiten afirmar que hay un alto grado de "culpa" del sionismo en la Shoá. En primer lugar queda claramente estipulado que "afirmamos la realidad de los asesinatos en masa judíos durante la Segunda Guerra Mundial” (NKUSA, 2007)

Se reconoce claramente la existencia de la Shoá, por lo que no es posible atribuir a este grupo actitudes negacionistas como las de otros exponentes en estas conferencias. No es equiparable la posición de Neturei Karta a la judeofobia árabe, que actualmente es de donde proviene la mayor animadversión hacia los judíos (Wistrich, 2005), porque ésta declara sin inconvenientes que la Shoá es un invento judío para sacar beneficios económicos o para establecer su dominio en Israel, mientras que Neturei Karta no pretende negar la historicidad de la Shoá. Sin embargo, la posición de este movimiento fundamentalista con respecto al sionismo tendría algún rasgo común con la judeofobia árabe porque ambos conciben que el sionismo "utiliza" la Shoá. Neturei Karta considera que "no hay justificación moral para lo que se hizo. Sin embargo, tampoco hay justificación moral para el uso de estos eventos para desposeer y ocupar otra gente que no tienen nada que ver con lo que se hizo en Europa" (NKUSA, 2006a) y "la realidad del Holocausto no debe utilizarse como pretexto para despojar al pueblo palestino, ya sea como individuos o colectivamente, de sus bienes y tierras" (NKUSA, 2007).

El sionismo intervino en la Shoá, impidió la salvación de miles de judíos para lograr su objetivo de obtener un Estado; luego cometió y comete acciones violentas contra el pueblo Palestino apelando a que las atrocidades sufridas en la Segunda Guerra Mundial no se repitan y actuando de manera similar con el pueblo Palestino (NKUSA, 2006b). Neturei Karta no es negacionista, pero su polémica presencia en estas conferencias se justifica porque consideran, al igual que la judeofobia árabe (y los negacionistas árabes), que la Shoá es manipulada por el sionismo y que este movimiento político comete acciones igual de deplorables -como las sufridas por los judíos- al atentar contra los palestinos.

La posición de Gush Emunim es diametralmente opuesta, porque con- 
cibe a la Shoá como un acontecimiento que conlleva al asentamiento en Israel. Para este movimiento religioso "todo estaba ocurriendo de acuerdo a una pauta preestablecida. Incluso el Holocausto había adelantado la salvación, porque había obligado a los judíos a dejar la Diáspora y retornar a la tierra" (Armstrong, 2009: 329).

Los judíos se habían asimilado en demasía durante la diáspora y, por lo tanto, había llegado la hora de volver a la Tierra Prometida: "Los judíos se habían 'aferrado con tal firmeza a la impureza de las tierras extranjeras que, cuando llegara el fin de los tiempos, serían reducidos con un gran derramamiento de sangre"' (Armstrong, 2009: 329).

Para Gush Emunim, la Shoá es considerada como un ejemplo de la disciplina de Dios, como una manera de coerción que Dios ejerce contra su pueblo elegido de modo que éste vuelva a la Tierra Prometida y también como una forma de hacerle sentir la necesaria urgencia de su reunificación (Lustick, 1987). Es interesante anotar que así como los miembros de Neturei Karta incriminaban abiertamente a los sionistas por la muerte de judíos en la Shoá; los sionistas también incriminan a la ultraortodoxia antisionista como "responsables de la amplitud de la matanza: al haber prohibido a sus fieles emigrar a Palestina, al haberse negado a organizarlos para resistir la 'solución final' hitleriana, habían facilitado la tarea de sus verdugos" (Kepel, 2005: 241).

Para el sionismo religioso, vertiente en la que se enmarca Gush Emunim, el exterminio de los judíos se incorpora a los argumentos que desacreditan a la ultraortodoxia, donde se ubicaría Neturei Karta, debido a su supuesta responsabilidad en éste; y justifican la creación del Estado de Israel (Kepel, 2005).

También es importante mencionar que ambos movimientos participan del conflicto en Medio Oriente y no precisamente para atenuarlo; se afirma esto porque Neturei Karta mantiene muy buenas relaciones con los enemigos de Israel, ya sea el mandatario iraní Ahmadinejad o Louis Farrakah de la Nación del Islam, y se orienta por el principio de que "el enemigo de mi enemigo, [el sionismo], es entonces mi amigo" (Herriot, 2009: 250), ya que la más hostil actitud es reservada al sionismo, el "enemigo interno", entonces, en comparación, los otros grupos son menos enemigos. El Gush considera que mientras los árabes como individuos se merecen respeto y un trato justo, los árabes que se oponen a la soberanía judía deben ser combatidos y exterminados (Zeidan, 2006), a éstos sólo les queda aceptar la legitimidad del sionismo. Estas dos actitudes claramente no disminuyen el conflicto en Medio Oriente; porque si se apoya a la causa palestina o cualquiera contra- 
ria al estado "herético" de Israel, como lo hace Neturei Karta, o si no se duda en abrir fuego contra los árabes para preservar la soberanía israelí; lo que se está haciendo o bien es establecer relación con el antagonista al sionismo, o bien defender a éste por todos los medios, pero de ninguna manera buscar una solución pacífica al conflicto.

\section{CONCLUSIONES}

La hipótesis señalada al comienzo de este artículo, que indicaba la existencia de dos visiones contrapuestas sobre la Shoá en los fundamentalismos judíos: una considerando el exterminio judío como un castigo divino y la otra como parte de un proceso que promueve el asentamiento definitivo en Israel, es corroborada a la luz de la documentación de Neturei Karta Internacional (NKUSA), en la cual se manifiesta claramente la culpa del sionismo en la Shoá y, en el caso de Gush Emunim, mediante los textos ya indicados que muestran cómo se concibe el exterminio como un aliciente para el asentamiento en Israel.

Entre las diferencias que se mencionaron entre ambos movimientos fundamentalistas la más notoria y antagónica era su posición con respecto al sionismo: unos condenándolo y otros adhiriendo a él. Se evidenció a lo largo de este artículo que el sionismo no sólo era la oposición más clara, sino que también constituía el punto central a partir del cual ambos movimientos concebían la Shoá. Para Neturei Karta el exterminio judío era producto de la pretensión sionista de terminar el exilio y por la no observancia estricta de la Torá; para Gush Emunim la Shoá promovía el asentamiento en Israel -argumentos que permiten corroborar la hipótesis de este artículo-. Para Neturei Karta el sionismo era culpable directo en la muerte de miles de judíos en la dictadura nazi y para el sionismo, del que es representante Gush Emunim en su vertiente religiosa, la ultraortodoxia antisionista no realizó, de igual manera, los esfuerzos debidos para salvar judíos durante el exterminio. Por lo tanto, la diferencia principal entre estos movimientos se constituía a su vez en el punto central en que se concebía, de forma antagónica, la Shoá.

\section{REFERENCIAS}

Armstrong, K. (2009). Los orígenes del fundamentalismo en el judaísmo, el cristianismo y el islam. Barcelona. Tusquets Editores. 
Avi-Hai, A. (1993). Danger! Three Jewish Peoples. New York: Shengold Publishers.

Azria, R. (1985) "Intégrisme Juif? ou la norme impossible". Social Compass, XXXII(4), 429-448.

Bauman, Z. (2001). La posmodernidad y sus descontentos. Madrid: Akal. (2003) Comunidad. En busca de seguridad en un mundo hostil. Argentina: Siglo XXI.

Bauman, Z. y Tester, K. (2002). La ambivalencia de la modernidad y otras conversaciones. Barcelona: Paidós.

Biletzky, E. (1981). Antisionismo. Nueva faz del antisemitismo. Tel-Aviv: Intersdar.

Caro, I. (2004). "Fundamentalismos judíos: Entre la reforma y la ortodoxia". Política y Estrategia, 94, 40-54.

(2008a). "Identidades judías contemporáneas en América Latina”. Atenea, 497, 79-93.

(2008b). "Oficialismo, Disidencia y nuevas identidades en el judaísmo chileno contemporáneo”. Persona y Sociedad. XXII(3), 67-92.

Giddens, A. (1999). Consecuencias de la modernidad. Madrid: Alianza.

Herriot, P. (2009). Religious fundamentalism. Global, local and personal. USA/ Canadá. Routledge.

Hilberg, R. (2005). La destrucción de los judios europeos. Madrid: Akal.

Hobsbawm, E. (1998). Historia del siglo XX. Buenos Aires: Crítica.

Kepel, G. (2005). La revancha de Dios. Cristianos, judios y musulmanes a la reconquista del mundo. Madrid: Alianza.

Kienzler, K. (2000). El fundamentalismo religioso. Madrid: Alianza.

Küng, H. (2007). El judaísmo. Pasado, presente, futuro. Madrid: Trotta.

Lustick, I. S. (1987). "Israel's dangerous fundamentalists". Foreign Policy, 68, 118-139.

Neuser, J. (1992). “El reto del fundamentalismo judío contemporáneo”. Concilium, 241(3), 85-90.

NKUSA (2006a). Talk prepared by Rabbi Yisroel Feldman of Neturei Karta International to be delivered at the International Conference to review the Holocaust, December 11-12, in Tehran, Iran. Recuperado el 12 de junio de 2010 de http://www.nkusa.org/activities/Speeches/2006Iran-Feldman.cfm (2006b). (International Conference "Review of the Holocaust", Teheran 1112 December '06) Speech delivered by Rabbi Aharon Cohen of Neturei Karta. Recuperado el 12 de junio de 2010 de http://www.nkusa.org/activities/ Speeches/2006Iran-ACohen.cfm

(2007). Why Went to Iran. Recuperado el 12 de junio de 2010 de http:// www.nkusa.org/activities/Statements/20070402IranWhycfm.cfm

Perednik, G. (1999). Judeofobia. Panamá: Imprenta Universitaria.

Thompson, G. F. (2007). "Religious fundamentalisms, territories and 'globalization'”. Economy and Society, 36(1), 19-50.

Wagner, P. (1997). Sociología de la modernidad. Madrid. Herder. 
Wistrich, R. (2005) "Negacionismo, antisionismo y antisemitismo". Nuestra Memoria, 25, 33-43.

Zeidan, D. (2006). "Jerusalem in Jewish Fundamentalism”. Evangelical Quarterly, 78(3), 225-236. 